\title{
Chapter 56 \\ WAVES ON THE PACIFIC COAST AND ON THE COAST OF ISE BAY CAUSED BY THE ISE-WAN TYPHOON
}

\author{
Takeshi Ifima, Dr. Eng., Shoji Satठ and Hisashi Aono \\ Harbor Hydraulics Division, Transportation \\ Technical Research Institute, \\ Ministry of Transportation
}

\section{SYNOPSIS}

General aspects of wave characteristics on the Pacific Coast of the main land and on the coast of Ise Bay caused by the Ise-wan Typhoon are studied on the bases of the observed wave data, calculated wave heights by the authors' method of forecasting shallow water wave and the results of the field inspection of damages by the typhoon.

\section{WAVES ON THE PACLFIC COAST}

\section{Waves on the Pacific Coast}

During this typhoon, wave observations were carried out at four harbors, namely Kochi, Naarai, Shimizu and Ishinomaki as shown in Fig. 3-1, by means of underwater pressure-type wave meters which were installed 6 10 meters deep, lest they should be affected by local condition. Fig. 3-3 shows the time change of height and period of significant wave, and velocity and direction of wind at each place. At the harbors of Hachlnohe and Kuji waves were measured by visual observation of wave staffs in the daytime only. As the results of observation, maximum signiflcant waves by the typhoon and the tzme of observation at above mentioned points are shown in Table 3-1.

Table 3-1

Maximum Significant Waves on the Pacific Coast

$\begin{array}{lllll}\text { Stations } & \begin{array}{l}\text { Heights } \\ \text { in Meters }\end{array} & \begin{array}{l}\text { Periods } \\ \text { in Seconds }\end{array} & \begin{array}{l}\text { Appearance } \\ \text { Times }\end{array} & \text { Remarks } \\ \text { Hachinohe } & 2.7 & 12.5 & 9 \text { a.m. 27th } & \text { Wind Waves (Staff) } \\ \text { Kuji } & 3.3 & 13.0 & 8 \text { a.m. 27th } & \text { Wind Waves (Staff) } \\ \text { Ishinomaki } & 4.0 & 11.0 & 6 \text { a.m. 27th } & \text { Wind Waves (Wave Meter) } \\ \text { Naarai } & 2.9 \sim 3.0 & 10.5 \sim 13.08 \text { a.m. 2 p.m. 26th Wind Waves (Wave Meter) } \\ \text { Shimizu } & 4.2 & 17.0 & 1 \text { a.m. 27th } & \text { Wind Waves (Wave Meter) } \\ \text { Kochi } & 6.5 & 14.4 & 8 \mathrm{p} \cdot \mathrm{m} .26 \text { th } & \text { Swells (Wave Meter) }\end{array}$

\section{Waves on the Kumano-Nada}

It is considered that the greatest waves on record attacked the coast of the Kumano-Nada, by the reasons that this coast situated in the dangerous semicircle of this typhoon and that its coast line was almost parallel to this course $0 \sim 80$ kilometers apart from the center of the 
Typhoon. Geographically the coast north of Kinomoto is sunken rias coast and its bottom profile is steeper than 1/10 within the depth of $-10 \sim-20$ meters. Accordingly, wave characteristics is so varied along the coast that the accurate estimation of wave distribution is very difficult. So the wave heights along the coast were estimated mainly from the inspection of damages of seawalls and breakwaters etc. and from the topogrphical features of the coast, the results being shown in Fig. 3-2.

It may be possible to estimate offshore wave characteristics which were not affected by coastal configuration, but the accuracy is obscure for such a large typhoon as this. The estimation from the observed wave data on the Pacific Coast caused by past typhoons and inspection of the degree of damages of coastal structures caused by this typhoon is that the significant wave height and period were 10 12 meters and 14 -16 sec., respectively, and the most prevailing wave direction was S SSW.

WAVES ON THE COAST OF ISE BAY

\section{Effect of Swell}

In this typhoon actual wave records were taken outside the harbors of Nagoya and Fukue. According to these data, at Nagoya height and period of swell were 10 15 centimeters and 7.3 9.0 sec. at 2 p.m. 26th of - September and at Fukue were 15 centimeters and $16.5 \mathrm{sec}$. at $5 \mathrm{a.m}$. 26th. On the other hand, according to the refraction diagram for the swell of $16 \mathrm{sec}$. and $\mathrm{S}-5^{\circ}-\mathrm{E}$, propagating through the Irako Channel, refraction coefficient is less than 0.02 on the coast from Yokkaichi to the Kiso River. So it may be unnecessary to consider the effect of swell and it is enough to consider waves generated only in the Bay.

2. Wind on the Bay during the Typhoon

Fig. 3-4 shows, as examples, wind distributions observed on the coast during this typhoon, in which arrow and number are wind direction and wind velocity and dotted line is the equi-wind velocity line. In addition, tide level obtained by tide gauges and equi-tidal lines estimated are shown, for which the datum is the mean water level of Tokyo Bay. In Fig. 3-5 and Fig. 3-6 time change of wind velocity and direction at the north, middle and south coasts of the Bay are shown. From these figures, wind characteristics by this typhoon are considered to be as follows.

(1) Wind velocity increases gradually from the south coast of the Bay to the north coast in advance of this typhoon and when it reaches the maximum on the north coast it begins to decrease on the south, that is, the maximum wind velocity on the south coast occurs $1.0 \sim 1.5$ hours earlier than on the north.

(2) After wind velocity comes up more than $15 \mathrm{~m} / \mathrm{sec}$, wind direction on the Bay is E $\sim E S E$, subsequently changes to $S E \sim S$ with the advance of the typhoon, and finally it becomes SW.

(3) Wind velocity on the west coast is larger than on the east coast except near Fukue and wind on the west coast may be considered nearly equal to the wind on the sea surface. 


\section{WAVES ON THE PACIFIC COAST AND ON THE COAST OF ISE BAY CAUSED BY THE ISE-WAN TYPHOON}

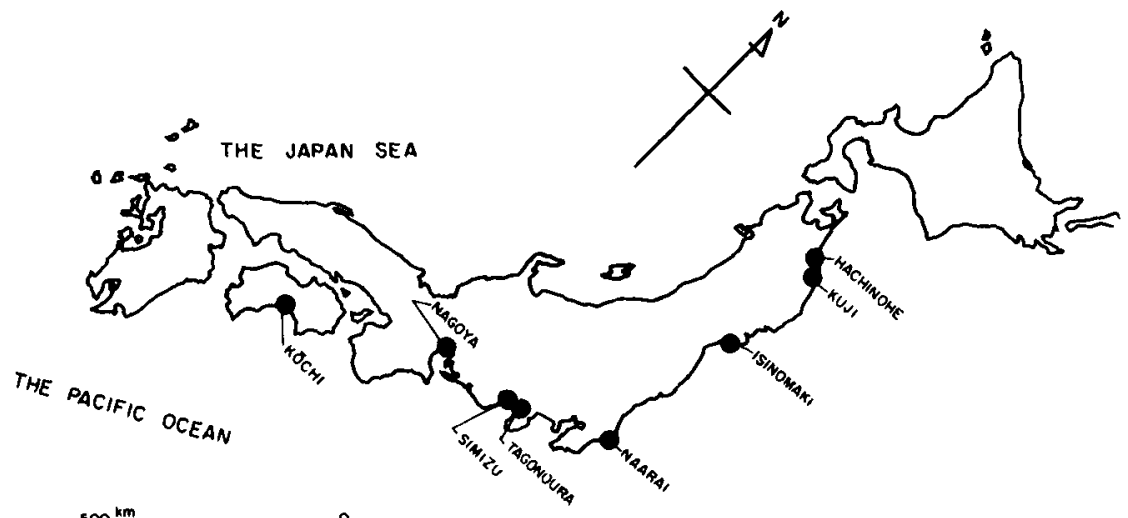

Fig. 3-1 Stations of Wave Observations.

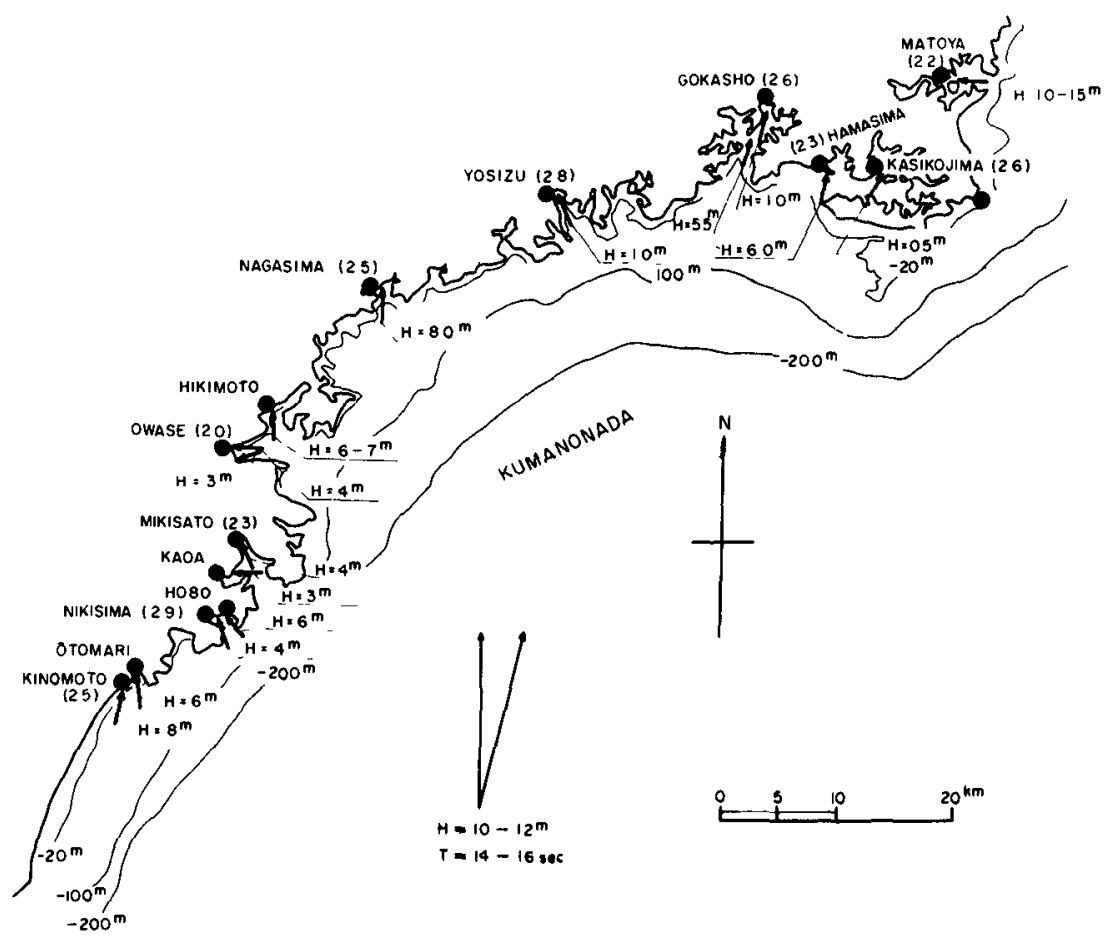

Fig. 3-2 Distribution of Predominant Significant Waves on the Kumano-Nada Coast. Arrows show Wave Direction. Numbers in Brackets are the Estimated Maximum Storm Tide Level above the Mean Water Level of Tokyo Bay. 
COASTAL ENGINEERING

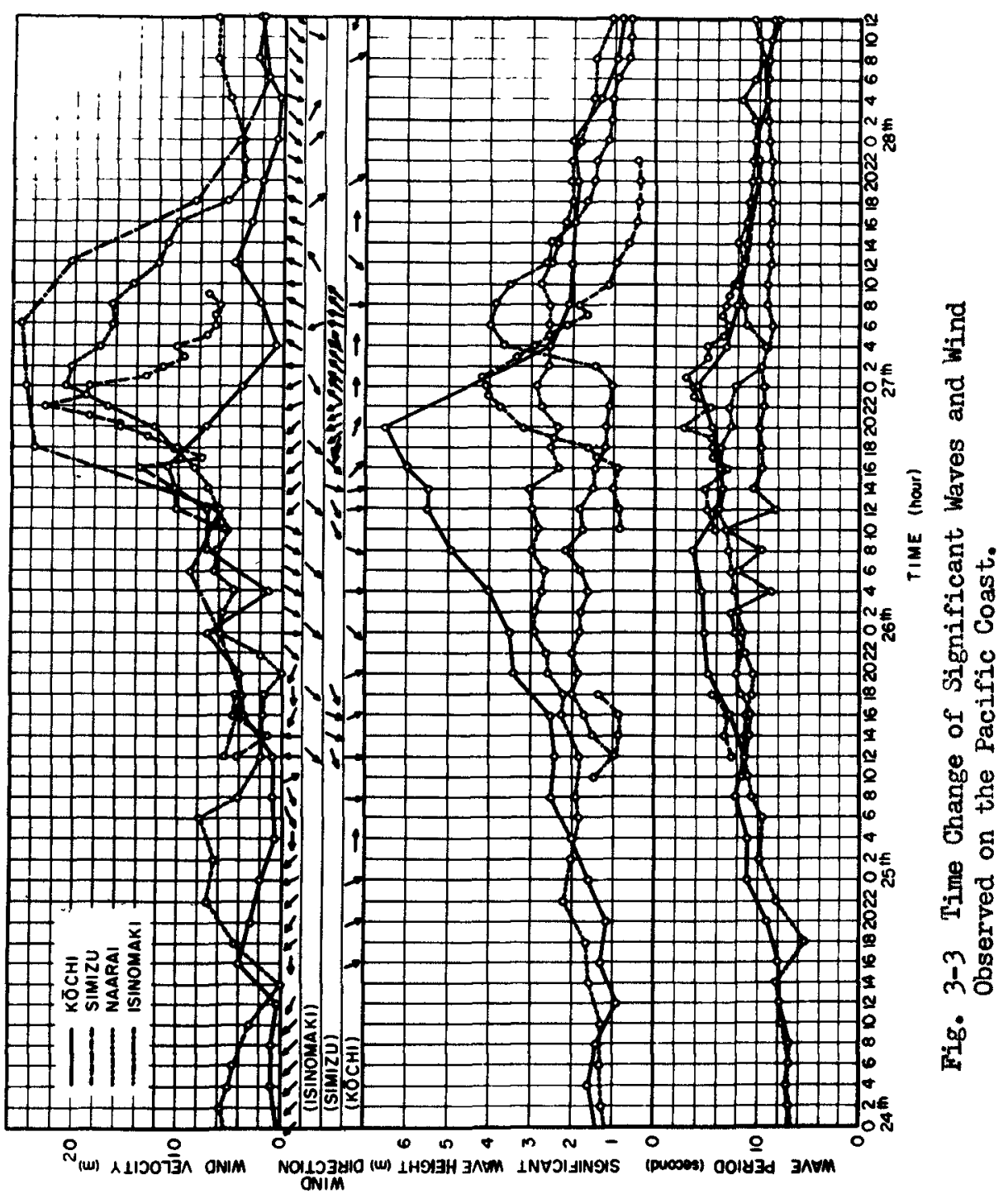




\section{WAVES ON THE PACIFIC COAST AND ON THE COAST OF ISE BAY CAUSED BY THE ISE-WAN TYPHOON}

We can not disregard wind distribution in examining wave characteristics in sheltered bays, even if their fetches are relatively short distance of 50 60 kilometers like as Ise Bay, especially in the case of irregular configuration and depth. Moreover, the change of depth with storm tide is as important as the change of wind. From the above considerations it is expected that waves on the west coast are larger than on the south coast, and that waves on the north coast become more larger with the progress of a typhoon than in stationary uniform wind velocity distribution.

\section{Wave Distribution from Observed Data and}

Investigation of Damages of Coastal Stmuctures

On the coast of the bay, during this typhoon wave records were taken at two stations off Nagoya Harbor and off Fukue Harbor.

Off Nagoya Harbor significant wave heights and periods were $2.0 \sim 2.4$ meters and 5.6 6.5 sec., respectively, from 6 p.m. till 11 p.m. 26th. Off Fukue Harbor the maximum significant wave caused at $7 \mathrm{p} . \mathrm{m}$. and its height and period were 1.7 meters and 5.2 sec. as shown in Fig. 3-15. Direction of the maximum significant wave were estimated to be $\mathrm{E} \sim \mathrm{ENE}$.

The distributzon of predominant wave height and wave direction estimated from the investigation of damages of the coastal structures, ie. seawalls, breakwaters, groins etc., after this typhoon is shown in Fig. 3-7. Although wave data shown in Fig. 3-7 were estimated mainly from the natural conditions at that time according to the authors' opinion, they are available together with calculated results which are described below, to examine wave characteristics.

4. Waves Estimated by Authors' Graphical

Calculation Method

Wave characteristics are estimated by the graphical calculation method as shown in appendix. Selecting 9 points on the coast of the Bay shown in Fig. 3-8, waves on the fetches in Fig. 3-8 are calculated in order to find the periodical change of wave height and period at 8 meters deep below the sea level datum. In order to eliminate subjectivities in calculations, distributions of wind and tide are assumed as follows :

(I) Ise Bay is seperated from open sea by Irako Channel and divided from Atsumi Bay by Nakayama and Morozaki Channels.

(2) Wind velocities and wind directions are determined from every hour distributions as shown in Fig. 3-4, because observed winds on the coast would give better results than estimated winds on the sea surface based on the winds on the coast and other meteorological conditions of this typhoon.

(3) The wind velocities on the leeward and windward-ends of the fetch are taken as fetch components of winds on the co ast as shown in Fig. 3-4. And the wind velocity on the fetch varies linearly from leeward to windward.

(4) Space and time change of depth on the fetch are given by the tide at the stations shown in Fig. 3-4 and the sea chart. 


\section{COASTAL ENGINEERING}

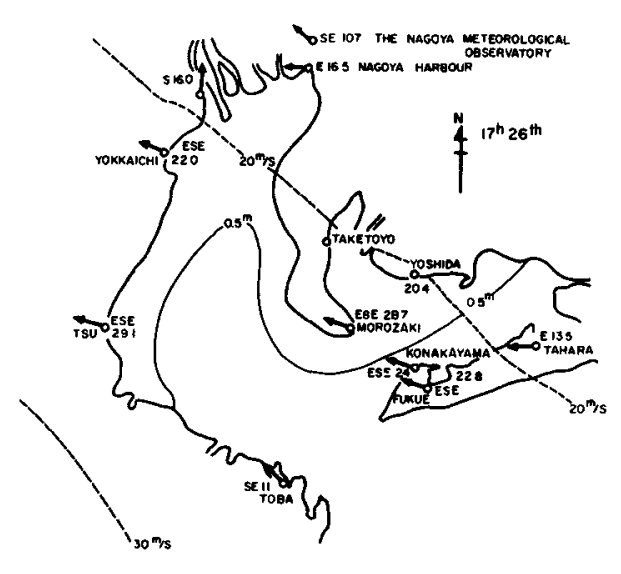

(a) 5 p.m. 26 th

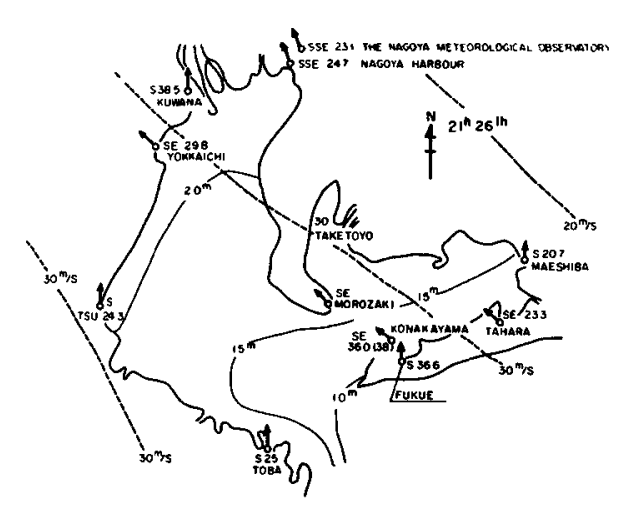

Fig 3-4 (c)

(c) 9 p.m. 26th

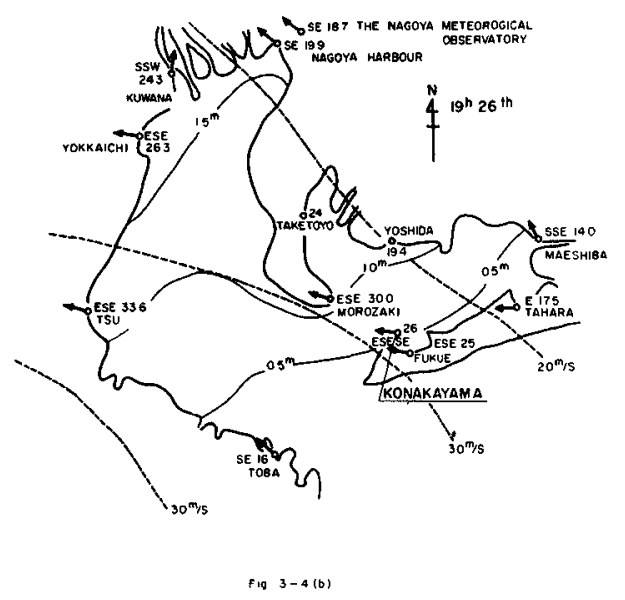

(b) 7 p.m. 26th

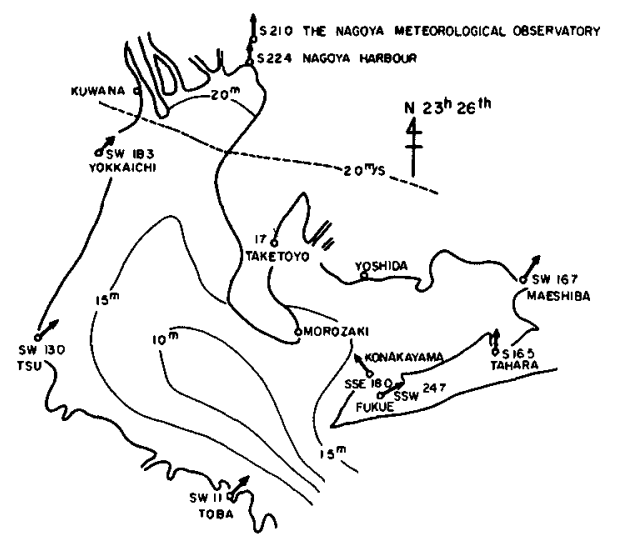

Fig 3-4(d)

(d) 11 p.m. 26 th

Fig. 3-4 Distribution of Wind and Fide on the Ise Bay during the Typhoon. 
WAVES ON THE PACIFIC COAST AND ON THE COAST OF ISE BAY CAUSED BY THE ISE-WAN TYPHOON

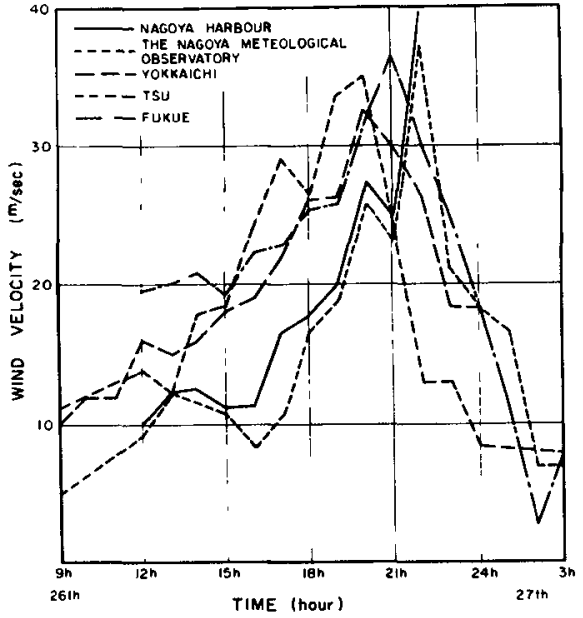

Fig. 3-5 Time Change of wind Velocity at Representative Points during the Typhoon.

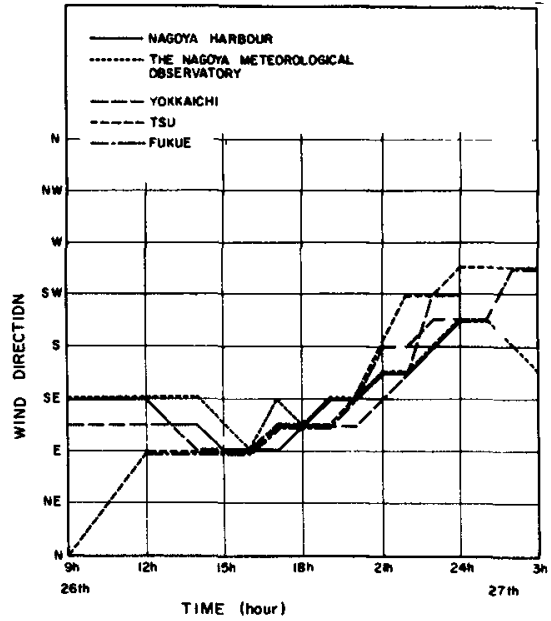

Fig. 3-6 Time Change of Wind Direction at Representative Points during the Typhoon.

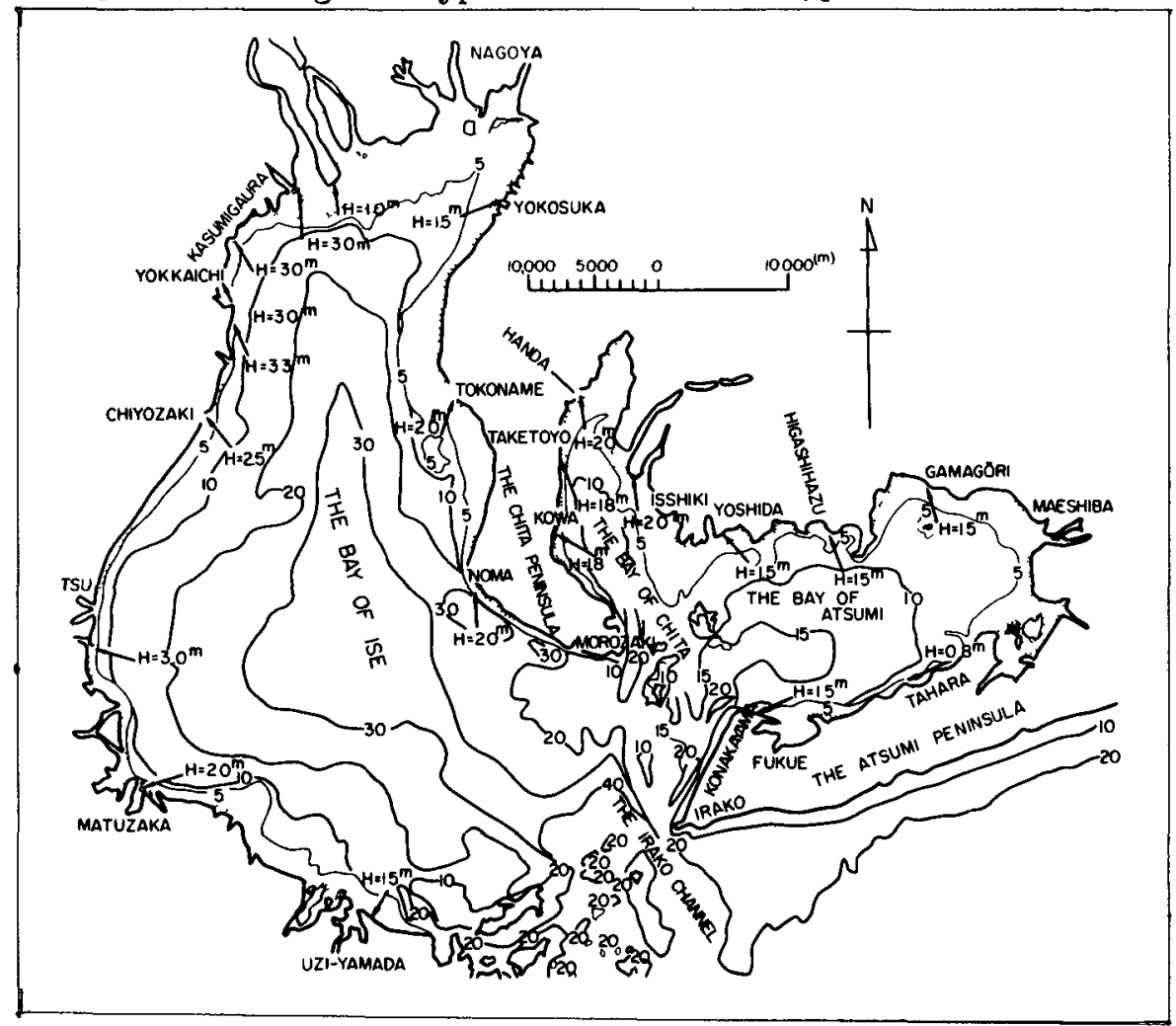

Fig. 3-7 Distribution of Predominant Significant Waves on the Ise Bay. 


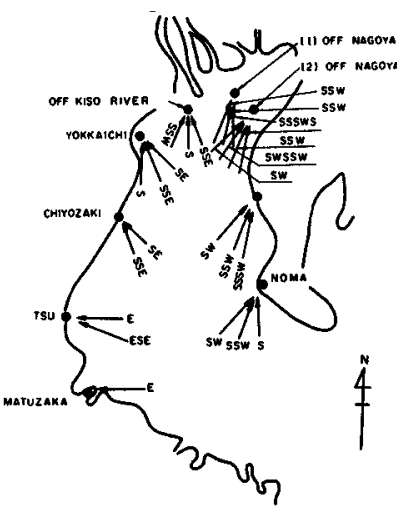

Fig. 3-8 Points of the Ise Bay on which Waves were Graphically Calculated.

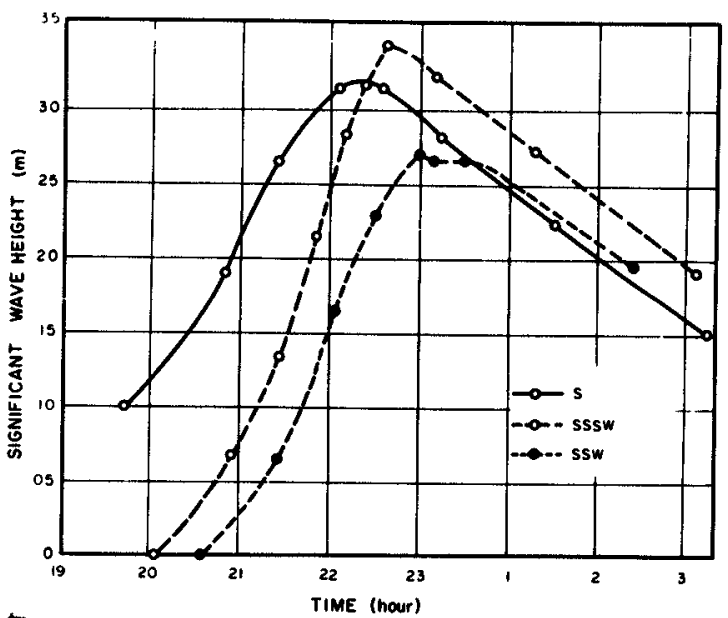

FIg. 3-10 Time Cnange of Significant Waves at Off Nagoya No. I for Variable Fetches.

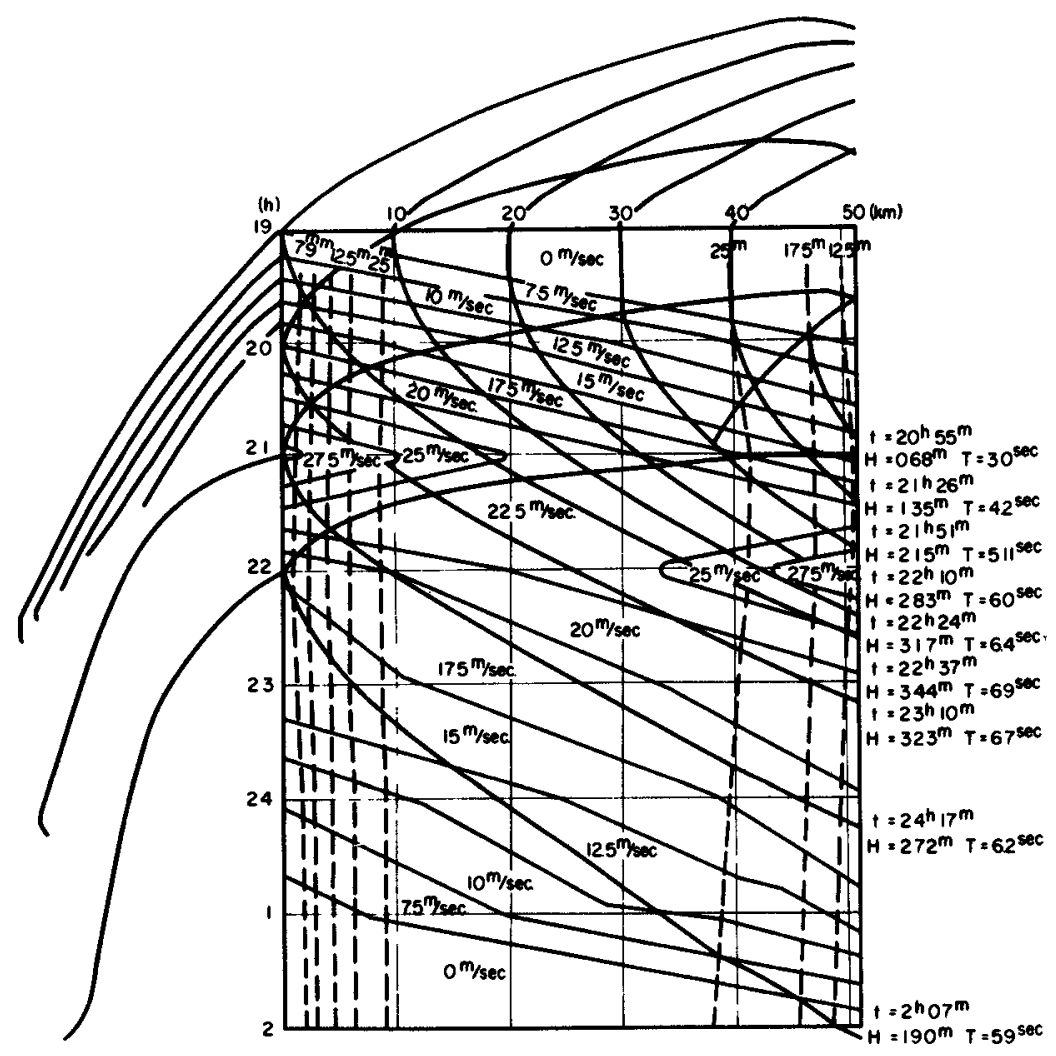

Fig. 3-9 Graphical Calculation of Significant Waves in the Direction of SSSW at Off Nagoya No.I. 


\section{WAVES ON THE PACIFIC COAST AND ON THE COAST OF ISE BAY CAUSED BY THE ISE-WAN TYPHOON}

By the wind field diagram which indicates space and time changes of wind velocity and depth on the fetch, wave heights, wave periods and travel times are calculated using $\mathrm{H}-\mathrm{t}-\mathrm{F}-\mathrm{Cg}$ diagram. Fig. 3-9 shows the wind field diagram of SSW direction at No. I off Nagoya, as an example. Time change of wave height of S, SSSW and SSW directions thus obtained at No. 1 off Nagoya is shown in Fig. 3-10. It is consider ed that the envelope of these curves gives time change of predominant wave heights. Time changes of predominant wave height at every point of the coast of the bay are shown in Fig. 3-11. Fig. 3-12 shows local characteristics of maximum significant waves, plotting the names of stations on the horizontal axis and maximum significant wave heights and periods and times of occurence on the vertical axis. The time of occurence of the maximum absolute wind and of the maximum component velocity on the feteh on which the maximum significant wave height occurs are plotted.

It is understood that wave characteristics on the coast of Ise Bay are as follow.

The maximum significant wave height and period increases graduallyk from Matsuzaka on the south coast to Yokkaichi on the north coast, where it attains the maximum value, and then decrease from Yokkaichi to the north and the east coasts. The minimum value occurs at Nagoya No. 2. In general wave heights and periods on the east coast are about $80 \%$ and $90 \%$ of the values on the west coast, respectively. The maximum wave on the north coast appears about 3 hours later than on the south coast. The maximum wind velocity at Nagoya occurs about 2.5 hours later than at Tsu, and the maximum wave heights at both of above two points appear about 1 2 hours later than the maximum wind velocity. Although wind is blowing from ESE near Yokkaichi and the maximum wind velocity occurs at 8 p.m., the maximum wave height occurs about $10 \mathrm{p.m}$. and the direction is SSE. Also, according to the results of actual inspection it is evident that waves from SSE direction destroyed structures on the coast near Yokkaichi. It is evident that the most predominant wave can not be decided only by the maximum wind relocity and its direction.

\section{Distribution of Wave around Nagoya Harbor}

In the previous section, we considered general distribution of waves in Ise Bay, but they should be considered as offshore waves because they are wares at the point of 8 meters deep. In actual the waves in front of seawalls piaced near the shoreline gives most important problem. Waves at these places have considerable local variation on accout of variation of water depth, therefore waves should be calculated in details for each place. As an example, results of calculations of wave distribution around Nagoya Harbor by the above mentioned method are shown here. Fig. 3-13 indictes the points of wave calculation, in which arrows are predominant directions of waves to them. Fig. $3-14$ is the wind field diagram of point $C$, and results of calculation for this point are shown in Table 3-2.

From Table 3-2, the wave is highest at the Point $A$, west side of Nagoya Harbor, where the maximum wave height exceeds 2 meters, and wave height decreases gradually to the east. (At the Point $E$, however, wave height comes up to 2 meters because of great water depth.) And at the 


\section{COASTAL ENGINEERING}

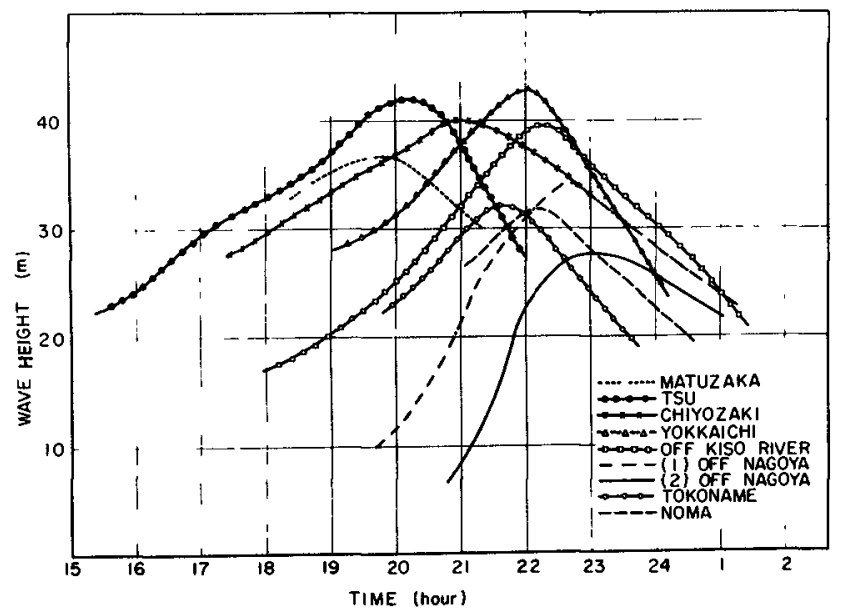

Fig. 3-11 Time Change of Predomunant Significant Wave Height on the Ise Bay.
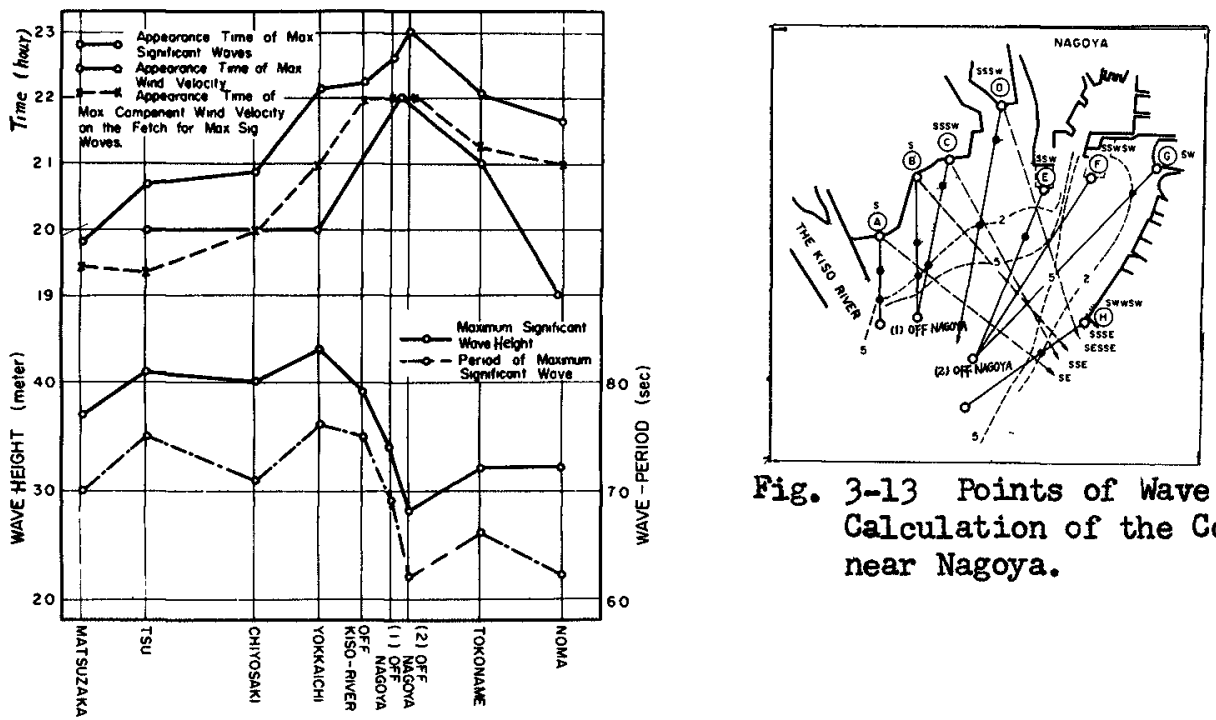

Fig. 3-13 Points of Wave Calculation of the Coast near Nagoya.

Fig. 3-12 Local Distributions of Maximum Significant Waves in 8 Meters Deep of Sea Chart and Maximuri Wind Velocity along the Coastline of the Ise Bay. 
WAVES ON THE PACIFIC COAST AND ON THE COAST OF ISE BAY CAUSED BY THE ISE-WAN TYPHOON

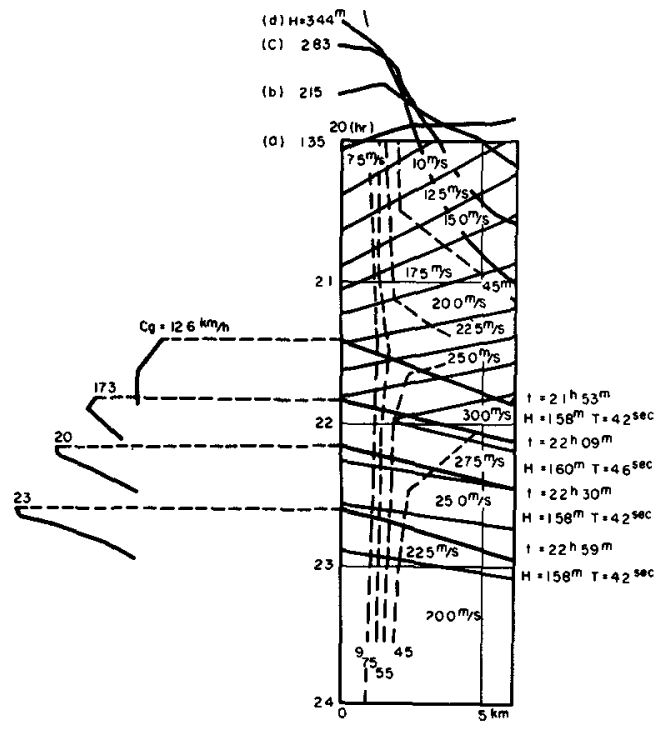

Fig. 3-14 Graphical Carculation of Significant Waves at Point $C$ of Nagoya.

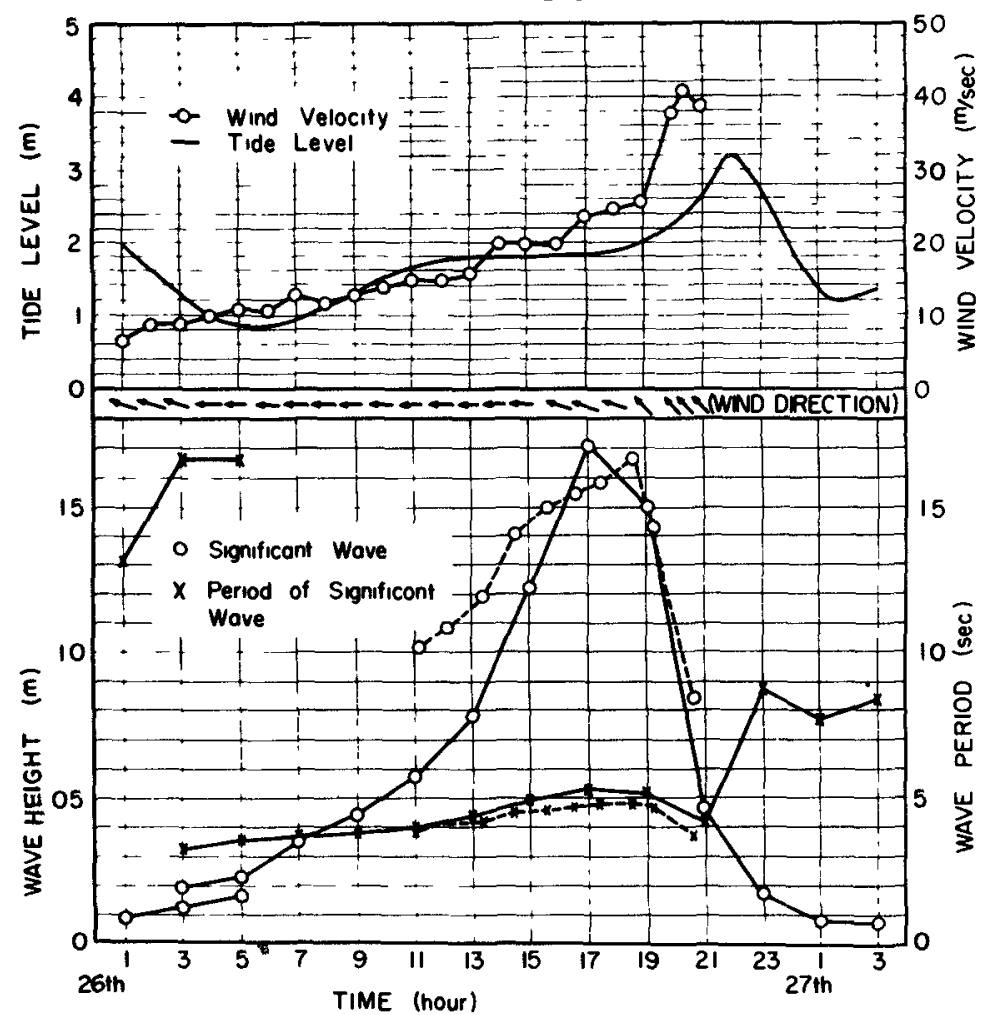

Fig. 3-15 Observed and Calculated Values of Significant Waves, and Tide and Wind at Konakayama, Fukue. Full Line is Observed and Dotted Line is Calculated. 


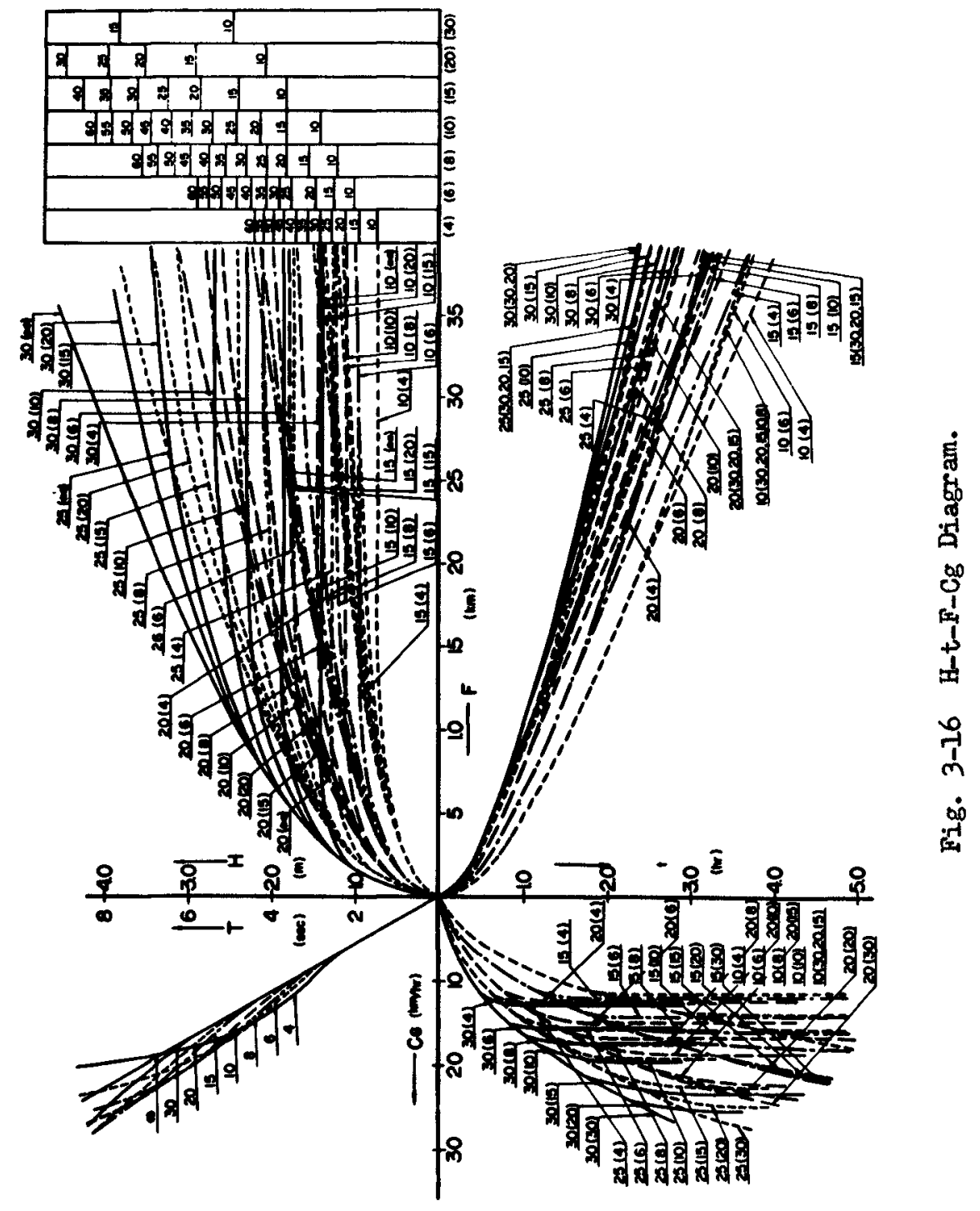




\title{
WAVES ON THE PACIFIC COAST AND ON THE COAST OF ISE BAY CAUSED BY THE ISE-WAN TYPHOON
}

\author{
Table 3-2 \\ Maximum Significant Waves \\ around the Port Nagoya
}

\begin{tabular}{|c|c|c|c|c|}
\hline Points & Directions & $\begin{array}{l}\text { Heights } \\
\text { in Meters }\end{array}$ & $\begin{array}{l}\text { Periods } \\
\text { in Seconds }\end{array}$ & $\begin{array}{l}\text { Appearance } \\
\text { Times }\end{array}$ \\
\hline $\mathbf{A}$ & $s$ & 2.20 & 5.8 & $8 \mathrm{~min} .10 \mathrm{p.m.}$ \\
\hline B & $\mathbf{s}$ & 1.90 & 5.4 & 59 min. 9 p.m. \\
\hline $\mathrm{C}$ & SSSW & 1.65 & 4.5 & 9 min. 10 p.m. \\
\hline D & SSSW & 1.65 & 4.6 & 6 min. 10 p.m. \\
\hline$E$ & SSW & 2.05 & 5.3 & 22 min. 11 p.m. \\
\hline $\mathbf{F}$ & $S S W \sim S W$ & 1.85 & 5.0 & $20 \mathrm{~min} .11 \mathrm{p} \cdot \mathrm{m}$. \\
\hline G & SW & 1.50 & 4.5 & 45 min. 0 a.m. \\
\hline $\mathrm{H}$ & $S W \sim W S W$ & 1.40 & 4.1 & $23 \mathrm{~min}$. \\
\hline
\end{tabular}

west side the highest wave and the maximum wind occurred simultaneously, but at the east side the highest wave occurs 1 $\sim 2$ hours later than the maximum wind. This phenomenon might be explained as follows. Since the bottom slope at the west side is very gentle, wave height decreases abruptly by the effect of bottom friction. As shown in the previous section the highest wave off Nagoya Harbor gets in this zone later than the maximum storm tide, and then lose its height by bottom friction. On the other hand, the maximum wind and the maximum level of storm tide occure simultaneously. Therefore in that time the bottom friction is not so effective because of great water depth. At the east side, water depth being not so small as the west side, the wave height is governed by wind more than by the increase of water depth by storm tide. Moreover, at that place, the time when component wind velocity of predominant wave direction comes up to the maximum is later than that of maximum storm tide, and the maximum height occurs later than the maximum component wind velocity. In this way, at the place of gentle slope like at the Points $A, B, C$ and $D$, the maximum storm tide and maximum wave height occur at the same time, and the coastal structure is exposed to danger. This is the reason why the degree of seawall damages near the Ibi River and the Kiso River is larger than the east coast from Yokosuka to Tokoname. The difference of degree of damages between the north coast and the south coast of Yokkaichi would be made clear by the same description.

\section{CONCLUSIONS}

The authors described the general characteristics of waves on the coast of the Ise Bay during the Ise-wan yphoon. It is summerized as follows.

(1) During Ise-wan Typhoon offshore waves seem to be the maximum on the coast of Kumano-Nada, wave height being 10 12 meters, period being $14 \sim 16$ seconds, and the prevailing wave direction being S SSW.

(2) It is considered that the prevailing significant wave height is the maximum of about 4 meters on the north-west coast and the minimum of about 2 meters near the coast of Nagoya Harbor. In general, wave height on the east coast is about $80 \%$ of the west coast.

(3) The maximum wave height on the north cosst is considered to occur later than on the south coast and $1 \sim 2$ hours later than the maximum wind velocity. 
(4) The time of occurence of the maximum wave height is considered to be dependent on the bottom slope and water depth, because waves near the shoreline are strongly affected by the bottom friction. Where the sea is very shallow, the maximum wave height would appear at the time of maximum sea level by the storm tide rather than at the time of maximum wind velocity.

(5) As shown in the appendix, it is considered that the results of graphical calculation in shallow water waves agree with the observed data. This method would be able to explain the characteristics of waves in moving fetches in shallow water.

\section{APPENDIX}

\section{GRAPHICAL METHOD OF FORECASTING WIND WAVES IN SHALLOW WATER}

\section{1) Forecasting of wind Waves in Shallow Water}

At present two main methods exist for shallow water wave forecasting, (a) the method of Thijsse and (b) the method of Bretschneider. The Thijsse's method is used only to forecast wind waves in the case of constant depth and constant wind speed. The Bretschneider's method is used to forecast wind waves in the case of a bottom of variable depth and constant wind speed, but when the depth varies with time calculation is very difficult.

During the time of this typhoon, the wind speed and the depth in Ise Bay varied with space and time, so that it is impossible to use those methods. Then, in order to forecast waves in such case, we extended irilson's graphical approach in deep water into shallow water. This method comes from the concept that waves generated on the windward end of fetch progress with group velocity, and that the group velocity and wave height vary continuously with wind speed and water depth, accordingly the change of wind speed and water depth do not give discontinuous change to wave characteristics.

In deep water waves, the law for decay of waves by decrease of wind speed is not given, so that it is impossible to calculate graphically the decay of waves in the case of abrupt decrease of wind speed. While, in shallow water waves, it is possible to calculate waves graphically in the case of decrease of wind speed and water depth, because the law for the decay of waves by bottom friction is given by Bretschneider and the law for the development of waves by wind is given by the relationship between $g H / \mathrm{U}^{2}$ and $\mathrm{gF} / \mathrm{U}^{2}$ in deep water.

\section{2) H-t-F-Cg Diagram}

Fig. 3-16 is the diagram for calculation of shallow water waves. On the diagram the horizontal axis is fetch and group velocity, and the vertical axis is wave height and travel time. The relations between wave height and fetch (wave height curves), fetch and time (propagation curves) and group velocity and time (group velocity curves) were shown in this diagram, and also the relation between group velocity and wave period is shown. The figures on the curves show wind speed and water depth, for 


\section{WAVES ON THE PACIFIC COAST AND ON THE COAST OF ISE BAY CAUSED BY THE ISE-WAN TYPHOON}

example, $30(20)$ corresponds to wind speed of $30 \mathrm{~m} / \mathrm{sec}$ and water depth of 20 meters.

Wave heights were calculated from the curve by Bretschneider showing the relation between $\mathrm{gH} / \mathrm{U}^{2}$ and $\mathrm{gF} / \mathrm{U}^{2}$ in shallow water of constant depth and the periods were given from the relation of $\mathrm{gH} / \mathrm{U}^{2}$ and $\mathrm{gT} / 2 \pi \mathrm{U}$ by S.M.B.

Thus, wave height and group velocity curves are drawn for each wind speed and fetch. $t$ The travel time $t$ when waves progress over fetch $F$ is obtained by $t=\int_{0} \mathrm{dF} / \mathrm{Cg}$. Moreover, on the righthand side of this diagram the wave heights for infinite fetch are shown for each water and wind speed.

\section{3) Comparsion with the Observed Values}

In order to confirm the reliability of this graphical method, the values obtained by the graphical method were compared with the observed waves out of Fukue Harbor during Ise-wan Typhoon. The wave heights and periods of significant waves obtained from the records of wave meter were shown in Fig. 3-15 together with tide, wind direction and wind speed at the same point. The maximum value of significant waves occurred at 7 p.m. 26 th and its wave height was 1.7 meters and period was 5.2 seconds. The direction of this wave was considered to be about ENE as assumed from the direction of wind and features of neighboring land.

It seems to be caused by the change of wind direction to SE (winds blowing from land) at $7 \mathrm{p.m}$. that wave height decreased suddenly- at the same time. We made the wind field diagram of ENE direction as shown in Fig. 3-9.

The results of calculation of the waves were shown in Fig. 3-15. Though the calculated periods are somewhat smaller than the observed values, the changes of wave heights and periods and the appearance time of maximum values estimated by calculation agree fairly well with those by observation.

\section{REFERENCES}

C.L.Bretschneider, Generation of wind Waves over a Shallow Bottom: Tech. Memo. No. 51, Beach Frosion Board, Oct. 1954.

C.I.Bretschneider, Revisions in Wave Forecasting Deep and Shallow Water; Proc. 6th Conf. Coast. Eng. Council on Wave Research, The Engineering Foundation, 1958.

B.G.Wilson, Graphical Approach to the Forecasting of Waves in Moving Fetches: Tech. Memo. No. 73, Beach Erosion Board, April 1955. 